\title{
Intracardiac Lethal Injection and Exsanguination Euthanasia
}

National Cancer Institute

\section{Source}

National Cancer Institute. Intracardiac Lethal Injection and Exsanguination Euthanasia. NCI Thesaurus. Code C116230.

A method of euthanasia whereby a subject is given a lethal intracardiac injection and the body is drained of blood. 